\title{
BMJ Open Social capital, neighbourhood characteristics and utilisation of local public health services among domestic migrants in China: a cross- sectional study
}

Zhiyuan Hou, ${ }^{1}$ Senlin Lin, ${ }^{1}$ Donglan Zhang $^{2}$

To cite: Hou Z, Lin S, Zhang D. Social capital, neighbourhood characteristics and utilisation of local public health services among domestic migrants in China: a crosssectional study. BMJ Open 2017;7:e014224. doi:10.1136/ bmjopen-2016-014224

- Prepublication history and additional material are available. To view these files please visit the journal online (http://dx.doi org/10.1136/bmjopen-2016014224)

$\mathrm{ZH}$ and SL contributed equally.

Received 9 September 2016 Revised 13 April 2017 Accepted 9 June 2017

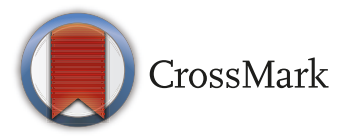

${ }^{1}$ Department of Social Medicine, School of Public Health, National Key Laboratory of Health Technology Assessment (Ministry of Health),

Collaborative Innovation Center of Social Risks Governance in Health, Fudan University, Shanghai, China

${ }^{2}$ Department of Health Policy and Management, College of Public Health, University of Georgia, Athens, Georgia, USA

Correspondence to

Dr Donglan Zhang;

dzhang@uga.edu

\section{ABSTRACT}

Objectives We examined the association between structural social capital and public health services use, and explored the modifiable effect of neighbourhood factors on this association among domestic migrants in China.

Methods Data were from a 2014 nationally representative cross-sectional sample of domestic migrants aged 15-59 years in China. Survey-weighted logistic regression models were applied to assess the association between structural social capital, measured by participation in social organisations and social activities, and use of public health services. Interaction terms between neighbourhood urban status, neighbourhood composition and social capital were further assessed in the models.

Results Migrants who participated in social organisations were more likely to establish health records (OR 1.467, $95 \% \mathrm{Cl} 1.201$ to 1.793 ) and receive health education information (OR 1.729, 95\% $\mathrm{Cl} 1.484$ to 2.016 ) than those who did not. Participation in social activities was positively associated with establishing health records only in urban communities (OR 1.853, 95\% Cl 1.060 to 3.239), and it was positively linked to receiving health education information among those living with a higher percentage of local neighbours (OR 1.451, 95\% Cl 1.044 to 2.017).

Conclusions Structural social capital was related to an increased utilisation of local public health services among migrants. The findings of this study provided new evidence for the differential influences of social capital by neighbourhood characteristics in China, which suggested the importance to enhance social capital in rural/suburban communities and communities where the majority of the residents were migrants.

\section{INTRODUCTION}

Since the early 1980s, China has been experiencing a historically unprecedented level of domestic migration. According to the 2010 China Population Census, there were over 221 million internal migrants, which accounted for about $17 \%$ of the national population. ${ }^{1}$ In China's specific context, domestic migrants refer to individuals who move to other areas of the country but do not
Strengths and limitations of this study

- Structural social capital was related to an increased utilisation of public health services among domestic migrants in China.

- Participation in social activities was positively associated with establishing health records in urban communities rather than in rural/suburban communities.

- Participation in social activities was positively linked with receiving health education information only among those living with a higher percentage of local neighbours.

- We measured structural social capital at the individual level, and may not have captured social capital at the community level.

- We may not have fully controlled for local policy effect on the use of public health services.

possess the 'Hukou' (residence registration certificates) of where they live. Since many public policies and social welfare programmes were implemented based on the long-established 'Hukou' system, those rural-to-urban migrants often faced obstacles to accessing local healthcare services. ${ }^{23}$

In China, public health services are mainly delivered by community health facilities. To strengthen preventive care in the healthcare system, the Chinese central government launched a national programme in 2009, Equalisation of Essential Public Health Services, to provide free essential public health services to all Chinese people. ${ }^{4}$ The benefit package of this programme included establishment of health records, health education, and chronic disease management. To implement this programme, the government provided a subsidy of 15 Renminbi (RMB, US\$2.14 according to the exchange rate in 2009) per capita for community health 
facilities to deliver the defined package. The subsidy was further increased to $35 \mathrm{RMB}$ in 2014 (\$5.73 per capita according to the exchange rate in 2014). Despite the fact that many cities have issued policies aimed at equalising essential public health services between migrants and local residents with 'Hukou', previous studies have shown that migrants were less likely to receive public health services than local residents. ${ }^{5}$ For example, although establishing health records was necessary for disease prevention and treatment, only $23.8 \%$ of migrants had their health records established in 2013, which fell below the national recommendation of $75 \%$. In addition, more than half of the domestic migrants did not receive any health education on occupational safety and injury protection. ${ }^{6}$

Among various factors that may prevent migrants from receiving basic public health services, lack of social capital might be one that has been previously overlooked. Social capital is defined as the network resources through which individuals are able to access links to social culture, socioeconomic factors, politics and social changes for a common good. ${ }^{7}$ Structural social capital, measured by participation in social organisations and social activities, can potentially strengthen relationships among individuals and enhance cognitive social capital such as trust and a shared social norm in a society. ${ }^{8}$ However, a study on migrant workers from seven cities has shown that, in 2006 , only $25 \%$ of migrants had any contact with the community organisations in their residential areas, and more than $80 \%$ never sought help from the community organisations. ${ }^{9}$

Social capital may affect an individual's utilisation of public health services through two main pathways: the information pathway, and the norm or peer effect pathway. ${ }^{10-12}$ (1) The information pathway means that enhanced social capital can facilitate information sharing such as the information on availability of public health services in the neighbourhood. ${ }^{12}$ Information then becomes an enabling factor that affects healthcare use. (2) The norm pathway indicates both the shared belief and enforcement mechanism from peers. ${ }^{13}$ Through the norm pathway, enhanced social capital can transmit attitudes, values and norms within a group of individuals, and enhance the peer effects on healthcare use. In China, many public health services, especially health education, are often delivered within the communities, and community organisations such as the community committee play an important role in information exchange. Participation in organisations may help migrants obtain and share health information, and may reciprocally affect migrants' health-seeking behaviours through communication with peers within the organisations.

In addition, the relationship between social capital and utilisation of public health services may be modified by community characteristics. Migrants often live in rental housing where migrants congregate, and residential segregation is common between migrants and local residents in Chinese cities. ${ }^{14}$ Neighbourhood composition affects the quantity and quality of information that migrants can obtain. ${ }^{12}$ Living with local residents may help migrants get more information about local resources. Neighbourhood urban status is also linked with access to health services, ${ }^{11}$ since more healthcare resources are available in the urban than in the suburban communities.

Although ample literature has shown that lack of social capital may negatively impact health, ${ }^{15}{ }^{16}$ few studies have examined the effect of social capital on healthcare utilisation, and its differential effect by neighbourhood characteristics. The mechanism about how social capital affects healthcare utilisation is not entirely clear. ${ }^{717}$ The main body of literature exploring the relationship between social capital and public health services is derived from developed countries and has inconsistent findings, ${ }^{18-21}$ and there were few studies estimating this relationship in lower and middle income countries. ${ }^{22} 23$ These studies showed that different elements of social capital may have different effects on the access to healthcare. One study from a low-income population in New Mexico suggested that community participation had little impact on healthcare use. ${ }^{24}$ The effect of social capital may also depend on the type of healthcare services. One study in India showed that social capital with strong bonding ties was positively associated with professional healthcare, but negatively associated with preventive care. ${ }^{25}$

The relationship between social capital and utilisation of public health services and the modification effect of neighbourhood characteristics are extremely important when we study migrant populations, since there is a huge disparity in economic status across neighbourhoods in urban China. ${ }^{14}$ However, to date no such study has been conducted among domestic migrants in China. In this study, we hypothesised that structural social capital enhanced the local social network that promoted utilisation of public health services. We aimed to test this association, and to explore the differences in the association by neighbourhood characteristics among the domestic migrants in China.

\section{METHODS \\ Data and study design}

Data for this analysis came from the 2014 National Domestic Migrant Population Dynamic Monitoring Survey (NIMPDMS), conducted by the National Health and Family Planning Commission of China. ${ }^{26}$ One of the survey's purposes was to study specifically the social integration and health among domestic migrants. This was a cross-sectional and nationally representative survey of domestic migrants aged 15-59 years who did not have the 'Hukou' of the cities and had been living in those cities for more than 1 month; the survey covered eight cities including Beijing, Qingdao, Jiaxing, Xiamen, Shenzhen, and Zhongshan from Eastern China, Zhengzhou from Central China, and Chengdu from Western China (see online supplementary file 1), representing the regions where the majority of domestic migrants resided. 
The sample was drawn using the stratified multi-stage sampling method with the Probability Proportional to Size (PPS) approach. Within each city, neighbourhoods in urban or suburban areas were randomly selected using the PPS. In each selected neighbourhood, 20 individuals were randomly selected. Around 2000 migrants participated in the survey from each city, and the total sample included 15999 respondents from eight cities. Interviewers who were trained by staff from local health bureaus conducted the face-to-face interviews. This study was approved by the Ethics Committee of the School of Public Health, Fudan University, China. All participants gave written consents to the study group.

The survey covered six sections: (1) basic sociodemographic information including gender, age, marital status, family size, etc; (2) social economic factors including education, income and occupational status; (3) public health and medical services utilisation including establishment of health records, health education, medical insurance coverage and hospitalisation; (4) family planning services; (5) social capital and social integration including participation in social organisations, social activities, neighbourhood economic status, and community population composition; (6) general health including self-reported health status.

\section{Measures of utilisation of public health services}

In China, most public health services were provided by local health agencies including establishment of health records, as well as health education for infectious disease prevention, maternal health promotion, prevention of occupational diseases and injuries, and prevention of non-communicable diseases (NCDs). ${ }^{3}$ We used two indicators: having personal health records established in the city; and having received health education to measure service utilisation.

Public health services for migrants aimed to address three health problems: infectious diseases, reproductive health, and occupational disease and injuries. ${ }^{27}$ However, NCD prevention was given lower priority. Social capital therefore may have a larger impact on the awareness of and access to NCD prevention services than the three previously-provided public health services for migrants. Therefore, according to the content of the health education migrants received, we further categorised health education into three groups: only receiving health education information on prevention of infectious diseases, reproductive health, and occupational disease and injuries; receiving all information covering health knowledge on NCD prevention; not receiving health education information.

\section{Measures of social capital and neighbourhood characteristics}

Our study focused on social capital and neighbourhood characteristics. There are two distinctive concepts of social capital: structural social capital measured by individual organisation membership and civic participation; and cognitive social capital measured by trust, reciprocity, and mutual help. ${ }^{23} 28$ This study focused specifically on the structural social capital, operationalised by a person's organisation membership and social activity engagement. An individual's organisation membership was measured by self-report of being a member of the following organisations: (A) Union; (B) Volunteer's Association; (C) Party Branch; (D) Alumni Association; (E) Chamber of Commerce; (F) Townsmen Association; (G) Others. An individual's engagement in social activities included the following activities: (A) Community Arts and Entertainment; (B) Social Services; (C) Voting Activity; (D) Performance Evaluation Activity; (E) Owner's Committee Activity; (F) Neighbourhood Management Activity; (G) Others. Neighbourhood characteristics were captured by self-reported community urban status (urban vs rural/ suburban) and self-reported neighbourhood composition ( $>50 \%$ neighbours are local residents vs. $>50 \%$ neighbours are migrants).

\section{Statistical analysis}

The main objective of this study was to assess the association between structural social capital and public health services utilisation among migrants, and whether the association varied by neighbourhood characteristics. $\mathrm{X}^{2}$ tests were applied to compare the distributions of social capital, neighbourhood characteristics and individual sociodemographic characteristics by whether they utilised public health services. Multivariate logistic regressions were used to estimate the relationship of social capital, neighbourhood characteristics and their interactions with whether the respondent established health records and whether they received health education information. Wald tests were applied to test if the interaction terms were statistically significant. In the regression models, we adjusted for the following confounding factors: gender (female vs male), age groups in years (15-24 vs 25-34, 35-44 and 45-59), marital status (currently married vs unmarried), educational attainment (primary school or below vs middle school, high school, college degree or above), monthly income (<2000 RMB (\$320) vs 2000-3000 RMB, 3000$4000 \mathrm{RMB}$ and $>4000 \mathrm{RMB}$ ), employment status (working in private sectors vs working in state-owned corporations, working in international companies and unemployed), Hukou status (urban vs rural Hukou), types of migration (interprovincial migration vs within-provincial migration), years lived in the destination regions $(<1$ year vs $1-3$ years, 3-6 years and $>6$ years), ${ }^{3}$ and self-reported health status (excellent/very good/good health vs fair/poor health). City fixed effects were adjusted to account for differences in public health services between the cities. In a sensitivity analysis, we further applied multinomial logistic regressions to explore the association between social capital and the contents of the health education they received.

Sampling weights were included in all analyses to adjust for the complex survey design. Odds ratios (OR) and 95\% confidence intervals (95\% CI) were presented. All the analyses were performed using Stata 14.0 (StataCorp LP, College Station, TX, USA). 
Table 1 Prevalence of public health services use among migrants in China: the 2014 National Internal Migrant Population Dynamic Monitoring Survey $(n=15999)$

\begin{tabular}{ll}
\hline Utilisation of public health services & $\%$ \\
\hline Having health records & 23.33 \\
\hline Yes & 76.67 \\
\hline No & \\
\hline Having received health education information & 57.16 \\
\hline Yes & 42.84 \\
\hline No & \\
\hline Types of health education information received & 22.02 \\
\hline $\begin{array}{l}\text { Prevention of infectious diseases } \\
\text { Prevention of infectious diseases and non- }\end{array}$ & 35.14 \\
\hline $\begin{array}{l}\text { communicable diseases } \\
\text { None }\end{array}$ & 42.84 \\
\hline
\end{tabular}

Note: survey weights adjusted.

\section{RESULTS}

Table 1 provides the weighted prevalence of public health services use among the domestic migrants. Of the 15 999 respondents, $23.33 \%$ reported that they had health records established in the destination city and $57.16 \%$ reported that they had received health education information from their residential communities. Among those who received health education, $22.02 \%$ received information only focusing on prevention of infectious diseases, and $35.14 \%$ received education information on both infectious diseases and NCDs.

Table 2 shows the sample descriptive statistics. Overall, $27.13 \%$ and $32.61 \%$ of the respondents participated in social organisations and social activities. Among those who had established health records, $37.71 \%$ enrolled in social organisations and $48.84 \%$ participated in social activities, whereas among those without health records, $23.91 \%$ participated in social organisations and $27.68 \%$ in social activities $(\mathrm{p}<0.001)$. There was also a much higher proportion of respondents participating in social organisations and activities among those who had received health education information $(\mathrm{p}<0.001)$. Among the total respondents, $10.38 \%$ lived in neighbourhoods with $>50 \%$ of local residents, and $84.36 \%$ lived in urban communities. The majority of respondents were 25-44 years old, married, received education at the middle or high school levels, were employed in the private sector, and had rural Hukou. Those using public health services had a higher level of education and were less likely to work in the domestic private sector or be unemployed $(\mathrm{p}<0.001)$. Migrants migrating within a province and living longer in the destination city were more likely to use public health services $(p<0.001)$.

Table 3 presents the results of the logistic regressions estimating the association between structural social capital, neighbourhood characteristics and having established health records. Migrants who participated in social organisations (OR 1.467, 95\% CI 1.201 to 1.793) and social activities (OR $1.620,95 \%$ CI 1.329 to 1.976 ) were more likely to establish health records than those who did not. Living with a higher percentage of local neighbours (OR 1.329, 95\% CI 1.050 to 1.682) and living in urban communities (OR 1.735, 95\% CI 1.224 to 2.460) were also associated with a higher possibility of establishing health records. We further tested the interaction effects between social capital and neighbourhood characteristics, and found that the social activities were protective for establishing health records only among those who lived in urban communities (OR 1.853, 95\% CI 1.060 to 3.239). There was no significant interaction effect between social capital and neighbourhood composition.

table 4 presents the regression results on whether the respondents received health education. Migrants who enrolled in social organisations (OR 1.729, 95\% CI 1.484 to 2.016) and participated in social activities (OR 4.226, 95\% CI 3.555 to 5.024) were much more likely to receive health education information. Migrants who lived with a higher percentage of local neighbours were significantly associated with increased odds of receiving health education (OR 1.230, 95\% CI 1.031 to 1.467), but community urban status was not significantly associated with receiving health education (OR 1.194, 95\% CI 0.936 to 1.522 ). The interaction effects show that the protective impact of social activities on receiving health education information was significantly greater among those living with a higher percentage of local neighbours (OR 1.451, 95\% CI 1.044 to 2.017), while we observed no significant interaction effect between social capital and community urban status. Similarly, results from the multinomial logistic regressions show that participating in social activities was associated with a higher likelihood of receiving health education information including both prevention of infectious diseases and NCDs, particularly when they lived with a higher percentage of local neighbours (see online Supplementary file 2).

\section{DISCUSSION}

Using a national sample of domestic migrants in China, this study examined the relationship between structural social capital and use of public health services, and assessed the heterogeneous effects of social capital according to the neighbourhood characteristics. The results showed that while controlling for other resources and factors, structural social capital was related to a higher likelihood of utilising local public health services among migrants, and some positive associations were greater in urban than in rural/ suburban communities, or greater in communities with a higher percentage of local residents.

In particular, we found that engagement in social organisations or social activities were related to establishment of health records and receiving health education information, which may benefit migrants' health eventually. Social capital may impact health through the pathways of healthcare utilisation and lifestyle behaviours. Researchers from developed countries have shown that 


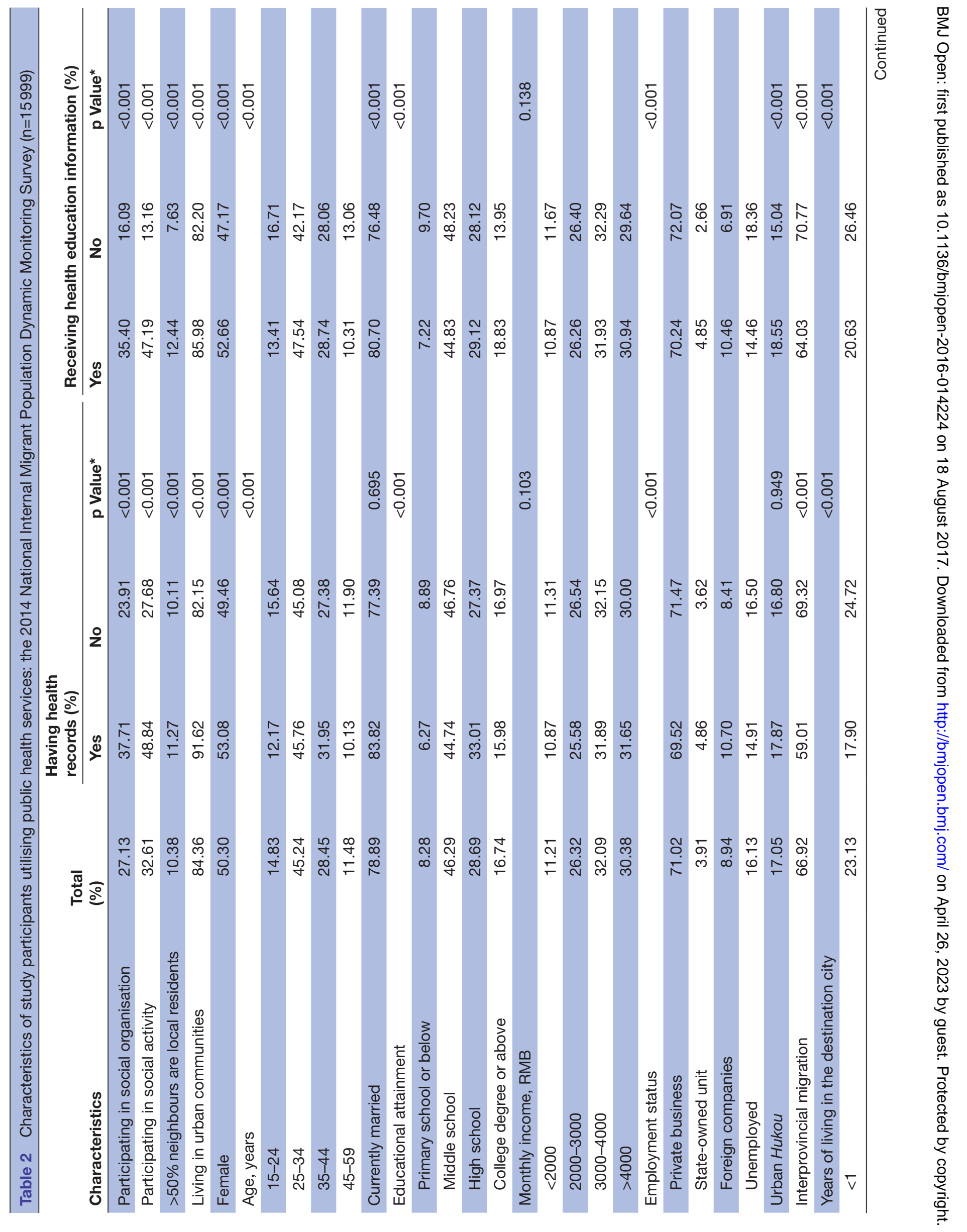




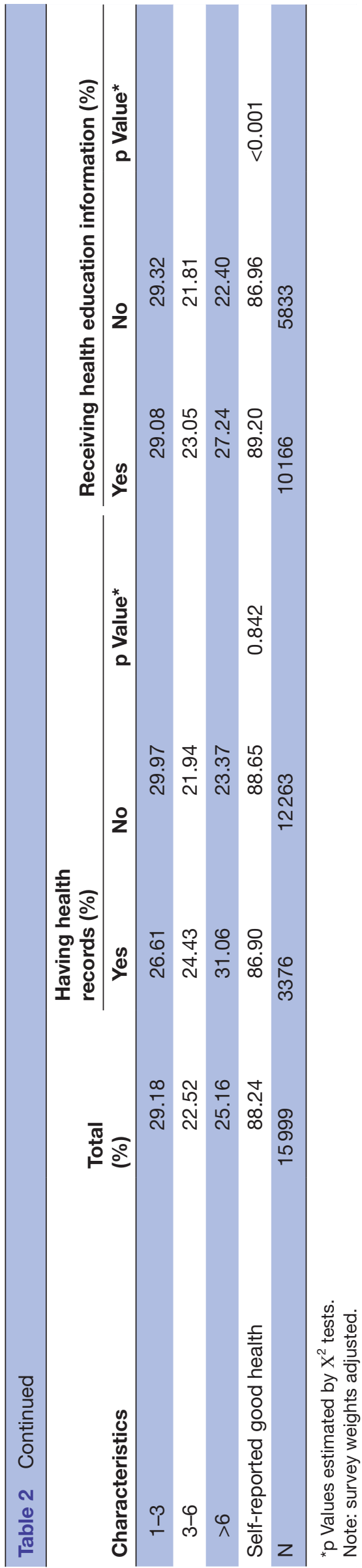

social capital is positively related to the utilisation of public health services, ${ }^{18} 202129$ which was consistent with our findings. For example, it was found that individuals with a higher social capital had a greater tendency to have health check-ups among a Danish population, ${ }^{18}$ or recall of health messages in the USA, ${ }^{30}$ increase women's utilisation of mammography screening in South Korea, ${ }^{31}$ and improve access to healthcare among low-income populations in the USA. ${ }^{21}$ Among African Americans, a higher level of social capital was associated with a greater likelihood of cancer screening. ${ }^{32}$ However, it is also noteworthy that social capital may increase the possibility of risky behaviours, such as smoking. It was found that social capital was positively associated with smoking behaviour in rural areas of South Korea. ${ }^{20}$ Smoking is a common behaviour for socialisation in China, especially among the migrant population. ${ }^{33}$ Future studies should therefore examine whether social capital has a negative impact on risky behaviours, besides its potential positive impact on promoting health education.

The reason why engagement in social organisation or activities might increase use of health services was because individuals, through those linkages, could exchange information and share their opinions with others within communities. But previous research among rural Chinese residents found that structural social capital (organisational membership) was not associated with health but cognitive social capital (trust and norm) was positively related with health. ${ }^{23}$ It was likely that engagement in social organisations or activities was more important for migrants who lived in new areas than local residents who already had established social ties with other people in the local areas. ${ }^{26}$ For migrants, engagement in social organisations or activities may help them better integrate into the destination city and obtain essential resources for health and prosperity.

Our findings on the main and modifiable effects of neighbourhood characteristics provided a more nuanced understanding of the impact of social capital on health. First, living in urban communities and in communities with a higher composition of local residents was associated with a higher likelihood of utilising public health services. This finding was consistent with a previous study conducted among immigrants in New York City, which showed that HIV/AIDS prevention behaviours were improved when immigrants had significantly more ties to people outside of their religious organisation. ${ }^{34}$ This may be explained by both physical and social environments of the communities. ${ }^{35}$ Migrants living in urban communities or with local neighbours may enjoy better access to healthcare, and are also more likely to get information. Second, the interaction effects were only significant for the impacts of participating in social activities, and this may be because in China most social activities are organised in the communities. In contrast, most social organisations are created by the companies, the chamber of commerce or townsmen. 
Table 3 Logit regressions of the association between structural social capital, neighbourhood characteristics and having health records established in the destination city: the 2014 National Internal Migrant Population Dynamic Monitoring Survey $(n=15999)$

\section{Having health records established}

\begin{tabular}{|c|c|c|c|}
\hline \multirow[b]{2}{*}{ Variables } & \\
\hline & No interaction & $\begin{array}{l}\text { Interaction with } \\
\text { neighbourhood } \\
\text { composition }\end{array}$ & $\begin{array}{l}\text { Interaction with } \\
\text { community urban status }\end{array}$ \\
\hline \multicolumn{4}{|l|}{ Structural social capital } \\
\hline Participating in social organisation & $1.467(1.201 \text { to } 1.793)^{\star \star \star}$ & $1.381(1.123 \text { to } 1.698)^{\star \star}$ & $1.900(1.143 \text { to } 3.158)^{\star}$ \\
\hline Participating in social activity & $1.620(1.329 \text { to } 1.976)^{\star \star \star}$ & $1.687(1.359 \text { to } 2.095)^{\star \star \star}$ & 0.966 (0.574 to 1.628$)$ \\
\hline \multicolumn{4}{|l|}{ Neighbourhood characteristics } \\
\hline$>50 \%$ neighbours are local residents & $1.329(1.050 \text { to } 1.682)^{\star}$ & 1.328 (0.987 to 1.788$)$ & $1.325(1.046 \text { to } 1.679)^{\star}$ \\
\hline Living in urban communities & $1.735(1.224 \text { to } 2.460)^{\star *}$ & $1.731(1.221 \text { to } 2.454)^{\star \star}$ & $1.541(1.044 \text { to } 2.276)^{\star}$ \\
\hline \multicolumn{4}{|c|}{ Interaction between social capital and neighbourhood characteristics } \\
\hline $\begin{array}{l}\text { Participating in social organisation }{ }^{*} \\
>50 \% \text { neighbours are local residents }\end{array}$ & & 1.300 (0.835 to 2.025$)$ & \\
\hline $\begin{array}{l}\text { Participating in social activity } \\
>50 \% \text { neighbours are local residents }\end{array}$ & & 0.839 (0.549 to 1.284$)$ & \\
\hline $\begin{array}{l}\text { Participating in social organisation* } \\
\text { Living in urban communities }\end{array}$ & & & $0.732(0.424$ to 1.265$)$ \\
\hline $\begin{array}{l}\text { Participating in social activity* } \\
\text { Living in urban communities }\end{array}$ & & & $1.853(1.060 \text { to } 3.239)^{\star}$ \\
\hline Constant & $0.030(0.017 \text { to } 0.052)^{\star \star \star}$ & $0.029(0.017 \text { to } 0.052)^{\star \star \star}$ & $0.032(0.018 \text { to } 0.057)^{\star \star \star}$ \\
\hline $\mathrm{R} 2$ & 0.107 & 0.108 & 0.109 \\
\hline
\end{tabular}

Significance levels: ${ }^{* * *} \mathrm{p}<0.001 ;{ }^{* *} \mathrm{p}<0.01 ;{ }^{*} \mathrm{p}<0.05$.

Data presented as OR, $95 \% \mathrm{Cl}$.

Models adjusted for all individual characteristics including gender, age, educational attainment, income status, marital status, employment status, migration type, years of living in the destination city, self-reported being in good health and city fixed effects.

Community characteristics may not influence the relationship between organisation membership and use of local public goods. In addition, migrants tend to live in rental housing where migrants congregate, or temporary housing such as dormitories established in workplaces. ${ }^{33}$ In our study, only $10 \%$ of migrants lived in neighbourhoods where more than half were local residents. This suggested that migrants were more likely to construct social networks with only migrants. Migrants who lived with local residents may be more likely to participate in community-based social activities from which the migrants may benefit reciprocally from an enhanced connection with local residents.

This study has several limitations. First, we did not have community-level social capital measures in the data. In addition, variables in neighbourhood characteristics were also measured from individual responses rather than from external sources. Questions were asked among individual respondents, which may be susceptible to recall bias. Further analysis should ascertain such information at the community level. Second, policy implementation may be primarily local. In our study, delivery of public health services to migrants may vary across cities and communities, on which we did not have information. Nevertheless, we included neighbourhood characteristics and city-fixed effects in the analysis to partly account for variations in policy implementation. Third, due to a limited number of domestic migrants participating in social organisations by neighbourhood characteristics, we were not able to classify and estimate what types of social organisations had the largest influence on health and health-related behaviours. Further analysis could provide greater detail about the different effects of social organisation participation.

In summary, social capital may be associated with an increased utilisation of public health services among domestic migrants in China, and certain neighbourhood characteristics may enhance this protective effect. The findings of this study provided new evidence for the differential influences of social capital by neighbourhood characteristics in China. In order to improve the use of public health services and overall health status, more interventions should be implemented to enhance social capital among migrants in suburban communities and communities where the majority of the residents are migrants. Specifically, outreach social services should be encouraged in suburban or segregated communities to help migrants participate in community organisations and activities, and build diverse social networks. ${ }^{36}$ 
Table 4 Logit regressions of the association between structural social capital, neighbourhood characteristics and receiving health education: the 2014 National Internal Migrant Population Dynamic Monitoring Survey $(n=15999)$

\section{Receiving health education}

\begin{tabular}{|c|c|c|c|}
\hline \multirow[b]{2}{*}{ Variables } & \multicolumn{3}{|l|}{ 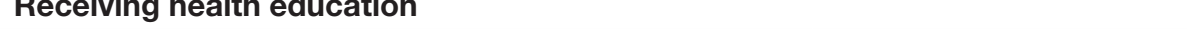 } \\
\hline & No interaction & $\begin{array}{l}\text { Interaction with } \\
\text { neighbourhood } \\
\text { composition }\end{array}$ & $\begin{array}{l}\text { Interaction with } \\
\text { community urban status }\end{array}$ \\
\hline \multicolumn{4}{|l|}{ Structural social capital } \\
\hline Participating in social organisation & $1.729(1.484 \text { to } 2.016)^{\star \star \star}$ & $1.806(1.540 \text { to } 2.119)^{\star \star \star}$ & $1.776(1.299 \text { to } 2.429)^{\star \star \star}$ \\
\hline Participating in social activity & $4.226(3.555 \text { to } 5.024)^{\star \star *}$ & $3.944(3.286 \text { to } 4.734)^{\star \star *}$ & $4.084(2.935 \text { to } 5.682)^{* \star \star}$ \\
\hline \multicolumn{4}{|l|}{ Neighbourhood characteristics } \\
\hline$>50 \%$ neighbours are local residents & $1.230(1.031 \text { to } 1.467)^{*}$ & $1.183(0.956$ to 1.464$)$ & $1.230(1.031 \text { to } 1.466)^{\star}$ \\
\hline Living in urban communities & 1.194 (0.936 to 1.522$)$ & $1.193(0.935$ to 1.522$)$ & $1.192(0.914$ to 1.556$)$ \\
\hline \multicolumn{4}{|c|}{ Interaction between social capital and neighbourhood characteristics } \\
\hline $\begin{array}{l}\text { Participating in social organisation* } \\
>50 \% \text { neighbours are local residents }\end{array}$ & & 0.785 (0.552 to 1.118$)$ & \\
\hline $\begin{array}{l}\text { Participating in social activity } \\
>50 \% \text { neighbours are local residents }\end{array}$ & & $1.451(1.044 \text { to } 2.017)^{\star}$ & \\
\hline $\begin{array}{l}\text { Participating in social organisation* } \\
\text { Living in urban communities }\end{array}$ & & & $0.962(0.673$ to 1.377$)$ \\
\hline $\begin{array}{l}\text { Participating in social activity* } \\
\text { Living in urban communities }\end{array}$ & & & $1.047(0.711$ to 1.540$)$ \\
\hline Constant & $0.243(0.150 \text { to } 0.393)^{\star \star \star}$ & $0.247(0.153 \text { to } 0.400)^{\star \star \star}$ & $0.244(0.149 \text { to } 0.397)^{\star \star \star}$ \\
\hline $\mathrm{R} 2$ & 0.192 & 0.193 & 0.192 \\
\hline
\end{tabular}

Significance levels: ${ }^{* *} \mathrm{p}<0.001 ;{ }^{* *} \mathrm{p}<0.01 ;{ }^{*} \mathrm{p}<0.05$

Data presented as OR, $95 \% \mathrm{Cl}$.

Survey weights adjusted. Models adjusted for all individual characteristics including gender, age, educational attainment, income status, marital status, employment status, migration type, years of living in the destination city, self-reported being in good health and city fixed effects.

Acknowledgements We thank the National Health and Family Planning Commission of China for providing the data.

Contributors ZH, DZ, SL contributed to the conceptualisation and design of the study. ZH, SL analysed the data. SL drafted the manuscript, and DZ, ZH extensively revised the manuscript. All authors read and approved the final manuscript submitted.

Funding This work was supported by the National Nature Science Foundation (grant number 71403007) and Fundamental Research Funds for the Central Universities of China.

Competing interests None declared.

Patient consent Obtained.

Ethics approval School of Public health, Fudan University, China.

Provenance and peer review Not commissioned; externally peer reviewed.

Data sharing statement The data used in this paper were provided by the National Health and Family Planning Commission of China. We signed a legally binding agreement with the Commission that we would not share the original data to any third parties. Although researchers who are interested can apply to get access to the data at http://www.moh.gov.cn//drks/s7848s/201510/8d4c69223d4c 49ca871fdd6fdc57aba5.shtml and Email: Idrkzxsj@163.com, it is up to the Nationa Health and Family Planning Commission to make the final decision.

Open Access This is an Open Access article distributed in accordance with the Creative Commons Attribution Non Commercial (CC BY-NC 4.0) license, which permits others to distribute, remix, adapt, build upon this work non-commercially, and license their derivative works on different terms, provided the original work is properly cited and the use is non-commercial. See: http://creativecommons.org/ licenses/by-nc/4.0/

(c) Article author(s) (or their employer(s) unless otherwise stated in the text of the article) 2017. All rights reserved. No commercial use is permitted unless otherwise expressly granted.

\section{REFERENCES}

1. Liang Z, Li Z, Ma Z. Changing patterns of the floating population in China during 2000-2010. Popul Dev Rev 2014;40:695-716.

2. Mou J, Griffiths SM, Fong H, et al. Health of China's rural-urban migrants and their families: a review of literature from 2000 to 2012. Br Med Bull 2013;106:19-43.

3. Hu X, Cook S, Salazar MA. Internal migration and health in China. Lancet 2008;372:1717-9.

4. Hou Z, Meng Q, Zhang Y. Hypertension prevalence, awareness, treatment, and control following China's healthcare reform. Am J Hypertens 2016;29:428-31.

5. Shaokang Z, Zhenwei S, Blas E. Economic transition and maternal health care for internal migrants in Shanghai, China. Health Policy Plan 2002;17(suppl 1):47-55.

6. guo Jing wh-y, zhou qing-yu. Status quo and determinants on basic public health services of floating population. Chinese Health Policy Res 2014;7:197.

7. Berkman LF, Glass T, Brissette I, et al. From social integration to health: Durkheim in the new millennium. Soc Sci Med 2000;51:843-57.

8. Lippman SA, Neilands TB, Leslie HH, et al. Development, validation, and performance of a scale to measure community mobilization. Soc Sci Med 2016;157:127-37.

9. Neal A. Social capital and community participation among migrant workers in China. J Community Psychol 2011;39:89-105.

10. Deri C. Social networks and health service utilization. $J$ Health Econ 2005;24:1076-107.

11. Prentice JC. Neighborhood effects on primary care access in Los Angeles. Soc Sci Med 2006;62:1291-303.

12. Devillanova C. Social networks, information and health care utilization: evidence from undocumented immigrants in Milan. $J$ Health Econ 2008;27:265-86.

13. Gibbs JP. Norms: the problem of definition and classification. AJS 1965;70:586-94.

14. Lu Y, Ruan D, Lai G. Social capital and economic integration of migrants in urban China. Soc Networks 2013;36:357-69. 
15. Murayama H, Fujiwara $\mathrm{Y}$, Kawachi I. Social capital and health: a review of prospective multilevel studies. J Epidemiol 2012;22:179-87.

16. Kawachi I, Kennedy BP, Glass R. Social capital and self-rated health: a contextual analysis. Am J Public Health 1999;89:1187-93.

17. Derose KP, Varda DM. Social capital and health care access: a systematic review. Med Care Res Rev 2009;66:272-306.

18. Bender AM, Kawachi I, Jørgensen T, et al. Neighborhood social capital is associated with participation in health checks of a general population: a multilevel analysis of a population-based lifestyle intervention- the Inter99 study. BMC Public Health 2015;15:694.

19. Klassen $A C$, Washington $C$. How does social integration influence breast cancer control among urban African-American women? Results from a cross-sectional survey. BMC Womens Health 2008;8:4.

20. Yun EH, Kang YH, Lim MK, et al. The role of social support and social networks in smoking behavior among middle and older aged people in rural areas of South Korea: a cross-sectional study. BMC Public Health 2010;10:78.

21. Perry M, Williams RL, Wallerstein $\mathrm{N}$, et al. Social capital and health care experiences among low-income individuals. Am J Public Health 2008;98:330-6.

22. Hollard G, Sene O. Social capital and access to primary health care in developing countries: evidence from Sub-Saharan Africa. J Health Econ 2016;45:1-11.

23. Yip W, Subramanian SV, Mitchell AD, et al. Does social capital enhance health and well-being? Evidence from rural China. Soc Sci Med 2007;64:35-49.

24. Perry M, Williams RL, Wallerstein N, et al. Social capital and health care experiences among low-income individuals. Am J Public Health 2008;98:330-6.

25. Story WT. Social capital and the utilization of maternal and child health services in India: a multilevel analysis. Health Place 2014;28:73-84.
26. Lin Y, Zhang Q, Chen W, et al. Association between social integration and health among internal migrants in ZhongShan, China. PLoS One 2016;11:e0148397.

27. Hu X, Cook S, Salazar MA. Internal migration and health in China. The Lancet 2008:372:1717-9.

28. Landstedt E, Almquist YB, Eriksson M, et al. Disentangling the directions of associations between structural social capital and mental health: longitudinal analyses of gender, civic engagement and depressive symptoms. Soc Sci Med 2016;163:135-43.

29. Oksanen T, Kivimäki M, Kawachi I, et al. Workplace social capital and all-cause mortality: a prospective cohort study of 28,043 public-sector employees in Finland. Am J Public Health 2011:101:1742-8.

30. Viswanath K, Randolph Steele W, Finnegan JR. Social capital and health: civic engagement, community size, and recall of health messagesAm J Public Health 2006;96:1456.61.

31. Lee CH, Kim YI. Effects of attitude, social influence, and selfefficacy model factors on regular mammography performance in life-transition aged women in Korea. Asian Pac J Cancer Prev 2015;16:3429-34.

32. Dean LT, Subramanian SV, Williams DR, et al. Getting black men to undergo prostate cancer screening: the role of social capital. Am J Mens Health 2015;9:385-96.

33. Chen X, Stanton B, Kaljee LM, et al. Social stigma, social capital reconstruction and rural migrants in urban China: a population health perspective. Hum Organ 2011;70:22-32.

34. Leung MR, Chin JJ, Petrescu-Prahova M. Involving immigrant religious organizations in HIV/AIDS prevention: the role of bonding and bridging social capital. Soc Sci Med 2016;162:201-9.

35. Leyden KM. Social capital and the built environment. Am J Public Health 2003;93:1546-51.

36. Kawachi I, Subramanian SV, Kim D. Social capital and health: Springer, 2008:1-26. 